\title{
TINJAUAN DESAIN STRUKTUR PORTAL GEDUNG ADMINISTRASI PUSAT STAIN SORONG
}

\author{
Slamet Widodo \\ Program Studi Teknik Sipil, Fakultas Teknik Universitas Muhammadiyah Sorong \\ Jl Pendidikan No 27 Kota Sorong \\ Email: slametwido2810@gmail.com
}

\begin{abstract}
Abstrak
Penelitian ini dilakukan dengan tujuan untuk mengetahui apakah kekuatan yang dihasilkan dari perencanaan dengan SRPMM sudah cukup menghasilkan kekuatan untuk menahan gayagaya yang bekerja pada struktur gedung yang ditinjau. Sistem struktur utama gedung Administrasi Pusat STAIN Sorong adalah Sistem Rangka Pemikul Momen (SRPM). Pada perencanaan sebelumnya digunakan metode SRPMK (Khusus) yang biasa digunakan untuk daerah dengan resiko gempa menengah atau tinggi. Untuk daerah Sorong yang termasuk Wilayah Gempa 4 (menengah), masih bisa digunakan metode SRPMM (Menengah), Sehingga sistem struktur pada perencanaan sebelumnya dimodifikasi menjadi SRPMM untuk mengetahui apakah SRPMM dapat menghasilkan struktur yang cukup kuat untuk menahan gaya-gaya yang terjadi pada struktur yang ditinjau. Dari tinjauan desain struktur portal yang telah dilakukan, dengan asumsi pembebanan yang sama pada konstruksi gedung yang sama, tetapi menggunakan metode perencanaan dengan sistem struktur yang berbeda, yang pada awalnya menggunakan Sistem Rangka Pemikul Momen Khusus (SRPMK), kemudian ditinjau dengan menggunakan Sistem Rangka Pemikul Momen Menengah (SRPMM), diperoleh desain yang memenuhi persyaratan keamanan untuk menahan gaya-gaya yang bekerja pada struktur portal gedung Administrasi Pusat STAIN Sorong. Sehingga perancangan struktur gedung ini seharusnya tidak perlu menggunakan SRPMK.
\end{abstract}

Kata Kunci: Tinjauan desain, Struktur portal

\section{Pendahuluan}

\section{Latar Belakang}

Pembangunan dalam berbagai sektor di kota Sorong terus berkembang dari waktu ke waktu. Salah satu sektor yang mengalami perkembangan ialah bidang jasa konstruksi bangunan gedung. Hal ini berkaitan erat dengan semakin meningkatnya taraf ekonomi dan kebutuhan hidup masyarakat. Untuk mendukung aktifitasnya dalam berbagai keperluan, manusia memerlukan adanya fasilitas fisik bangunan gedung seperti rumah tinggal, rumah sakit, gedung sekolah, gedung pemerintahan serta fasilitas-fasilitas pelayanan umum lainnya.

Agar bangunan gedung dapat memberikan rasa aman dan nyaman bagi penghuninya, perlu dilakukan suatu perencanaan struktur gedung yang kokoh dan kuat menahan beban. Bebanbeban yang umumnya diperhitungkan antara lain beban gravitasi (vertikal) dan beban lateral gempa (horizontal). Dalam SNI 03-1726-2002, Indonesia terbagi menjadi 6 wilayah gempa dengan tata cara perencanaan struktur yang berbeda, sesuai dengan kondisi kegempaan dari masing-masing wilayah.

Dalam peta zonasi gempa SNI 03-1726-2002, Kota Sorong masuk dalam wilayah gempa 4. Perencanaan struktur pada wilayah gempa 3 dan 4 yang merupakan daerah dengan resiko gempa sedang, sesuai SNI 03-1726-2002 digunakan metode SRPMM, tapi masih dibolehkan menggunakan metode SRPMK. 
Portal Gedung Administrasi pusat STAIN Sorong, direncanakan dengan menggunakan sistem struktur SRPMK. Akan tetapi menurut SNI 03-1726-2002, perencanaan struktur gedung pada wilayah gempa menengah bisa menggunakan sistem struktur SRPMM. Apakah SRPMM tidak cukup kuat untuk dipakai dalam perencanaan struktur gedung ini sehingga harus digunakan sistem struktur yang lebih kuat. Dengan pertimbangan di atas, penyusun merasa tertarik untuk melakukan penelitian dengan judul "Tinjauan Desain Struktur Portal Gedung Administrasi Pusat STAIN Sorong".

\section{Rumusan Masalah}

Apakah dengan asumsi pembebanan yang sama pada konstruksi gedung yang sama, tetapi menggunakan metode perencanaan dengan sistem struktur SRPM yang berbeda akan menghasilkan kekuatan yang cukup untuk menahan gaya-gaya yang bekerja pada struktur portal gedung Administrasi Pusat STAIN Sorong?

\section{Maksud dan Tujuan}

Adapun maksud dan tujuan dari tinjauan desain struktur portal gedung Administrasi Pusat STAIN Sorong ini adalah untuk mengetahui apakah kekuatan yang dihasilkan dari perencanaan dengan SRPMM sudah cukup menghasilkan kekuatan untuk menahan gaya-gaya yang bekerja pada struktur gedung yang ditinjau.

\section{Batasan Masalah}

Ruang lingkup yang diperhitungkan dalam penelitian ini antara lain :

1. Obyek penelitian adalah struktur portal gedung Adminstrasi Pusat STAIN Sorong.

2. Perencanaan meliputi perhitungan struktur portal bangunan atas, tidak termasuk struktur bawah.

3. Perencanaan struktur menggunakan mutu beton $\left(\mathrm{fc}^{\prime}\right)=20 \mathrm{Mpa}$, dan tulangan utama $\varnothing \leq$ $16 \mathrm{~mm}$ dengan tegangan leleh $(\mathrm{fy})=320 \mathrm{MPa}$.

4. Analisa mekanika struktur menggunakan program SAP 2000 v.7.40.

5. Kombinasi beban yang diperhitungkan adalah beban mati, beban hidup dan beban horizontal gempa mengambil WG 4 (kota Sorong dan sekitarnya).

6. Secara keseluruhan struktur beton direncanakan menggunakan tingkat daktilitas parsial dengan nilai $\mu=3,5$ dan $\mathrm{R}=5,6$.

\section{Metodologi}

\section{Desain Studi Kasus}

1. Wilayah Gempa

Wilayah gempa untuk perancangan gedung ini memakai wilayah gempa 4 dengan nilai Percepatan Puncak Efektif Batuan Dasar (PPEBD) atau Peak Ground Accelaration (PGA) = $0,20 \mathrm{~g}$, sehingga termasuk Resiko Gempa Sedang.

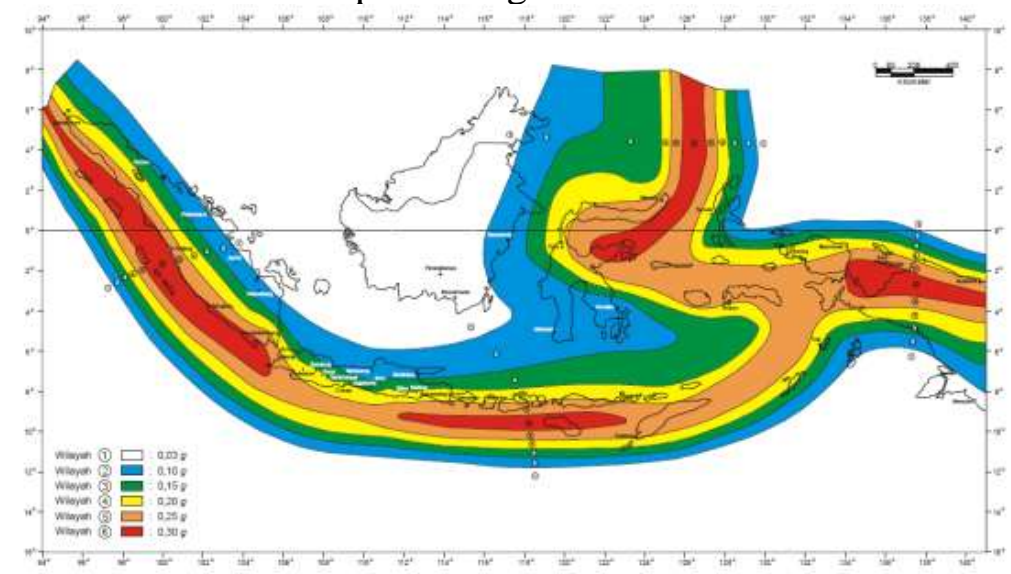

Gambar 1. Wilayah Gempa Indonesia Dengan Percepatan Puncak Batuan Dasar Dengan Periode Ulang 500 Tahun (SNI 03-1726-2002) 
2. Jenis Tanah

Jenis tanah setempat adalah tanah sedang.

3. Sistem Struktur

Karena perancangan gedung ini terletak pada zona gempa 4, maka perhitungan menggunakan metode Sistem Rangka Pemikul Momen Menengah (SRPMM).

4. Kategori Gedung

Menurut SNI 1726 Tabel 1, gedung ini termasuk "Gedung Umum" dengan Faktor Keutamaan (I) 1,0.

5. Konfigurasi Struktur Gedung

Konfigurasi gedung ini beraturan, karena memenuhi ketentuan yang diatur dalam SNI 1726 Ps. 4.2.1. Analisa gempa yang digunakan yaitu Analisis Statik Ekuivalen yang diatur dalam SNI 1726 Ps 6.

\section{Cara Pengumpulan data}

Pengumpulan Data \& Studi Literatur

1. Adapun sumber data yang diperoleh untuk penelitian ini sebagian besar didapatkan dari PT Primakarya Estetika Engineering Consultant yang merupakan konsultan perencana gedung Administrasi Pusat STAIN Sorong. Data-data yang diperoleh menerangkan dasardasar perencanaan sebelumnya untuk kemudian dijadikan referensi dalam proses penelitian.

2. Data-data dan literatur yang berhubungan dengan ketekniksipilan juga dikumpulkan sebagai tambahan materi. Selain itu informasi lainnya juga didapatkan dari internet mengenai peraturan-peraturan maupun artikel yang relevan dengan tema penelitian ini

\section{Cara Pelaksanaan Studi Kasus}

1. Modifikasi \& Kriteria Pemilihan Struktur

Sistem struktur utama gedung Administrasi Pusat STAIN Sorong adalah Sistem Rangka Pemikul Momen (SRPM). Pada perencanaan sebelumnya digunakan metode SRPMK (Khusus) yang biasa digunakan untuk daerah dengan resiko gempa menengah atau tinggi. Untuk daerah Sorong yang termasuk Wilayah Gempa 4 (menengah), masih bisa digunakan metode SRPMM (Menengah), Sehingga sistem struktur pada perencanaan sebelumnya dimodifikasi menjadi SRPMM untuk mengetahui apakah dengan SRPMM ini dapat dihasilkan struktur yang cukup kuat untuk menahan gaya-gaya yang terjadi pada struktur yang ditinjau.

Kategori gedung administrasi pusat diambil berdasarkan pedoman pada Tabel 1 (SNI 031726-2002) yakni kategori gedung perkantoran dengan faktor keutamaan (I1,I2,I3) = 1,0 .

2. Preliminary Design

Preliminary design dimaksudkan untuk mendapatkan dimensi penampang elemen struktur mula-mula untuk kemudian dianalisa lebih lanjut dalam tahapan perencanaan struktur.

3. Penentuan Permodelan Struktur

Model struktur yang ditinjau berupa portal 2 lantai dengan konfigurasi struktur yang beraturan. Kaki kolom diasumsikan terjepit pada pondasi.

4. Pembebanan

Pada tahap ini diperhitungkan beban-beban yang harus ditahan oleh struktur. Beban-beban yang dimaksud antara lain beban gravitasi (beban mati dan beban hidup) dan beban gempa. Perhitungan beban gempa mengikuti aturan dalam SNI 03-1726-2002. Adapun kombinasi pembebanan sesuai dengan ketentuan dalam SNI 03-2847-2002.

\section{Cara Analisis}

1. Analisa Struktur Menggunakan SAP 2000

Agar proses analisa struktur berjalan lebih efektif dan efisien, maka dalam tahapan analisa struktur digunakan program bantuan SAP 2000. Program SAP yang digunakan adalah SAP 2000 versi 7.40. 
2. Output Gaya Dalam Akibat Beban Gravitasi \& Gempa

Jika proses analisa struktur dengan SAP berjalan dengan baik (analysis Complete) maka diagram gaya geser (Shear Force) dan Bending Moment dapat ditampilkan. Proses desain penampang dapat dimulai.

3. Perencanaan Struktur Dengan Pedoman SNI 03-2847-2002 Dengan Ketentuan Untuk Perencanaan Gempa Dengan Sistem SRPMM

Perencaan struktur menggunakan pedoman SNI 03-2847-2002 dengan kriteria perencanaan dan syarat-syarat pendetailan untuk gedung dengan sistem struktur SRPMM.

4. Evaluasi \& Kontrol

Setelah melakukan analisa struktur gedung, selanjutnya kita kontrol hasil desain. Antara lain kontrol terhadap balok, kolom, dan juga perhitungan hubungan balok dan kolom, dimana dari kontrol tersebut dapat diketahui apakah desain yang kita rencanakan telah sesuai dengan syarat-syarat perencanaan, dan peraturan angka keamanan. Bila telah memenuhi syarat maka dapat diteruskan ke tahap pendetailan. Bila tidak memenuhi syarat maka harus dilakukan perencanaan ulang.

5. Penggambaran Hasil Perencanaan

Setelah melalui tahap evaluasi dan kontrol, berikutnya hasil dari perencanaan elemenelemen portal. tersebut didetailkan dalam bentuk gambar. Gambar-gambar ini menerangkan penampang elemen struktur balok dan kolom beserta konfigurasi penulangannya. Penggambaran hasil perencanaan ini menggunakan program bantu AutoCAD.

Semua metode penulisan dan analisa dalam artikel ilmiah ini merujuk pada panduan penulisan tugas akhir Fakultas Teknik Universitas Muhammadiyah Sorong tahun 2014 (Pristianto, Amri, \& Rusdi, 2014).

\section{Hasil dan Pembahasan}

A. Preliminary Design

1. Dimensi balok

a. Balok induk bentang $(\ell)=500 \mathrm{~cm}$

$h=\frac{500}{16}\left(0,4+\frac{320}{700}\right)=26,79 \mathrm{~cm}$

$\approx 30 \mathrm{~cm}$

$1,5 \leq \frac{30}{b} \leq 2 \Rightarrow \mathrm{b}=20 \mathrm{~cm}$

dimensi balok induk $20 / 30 \mathrm{~cm}$

b. Balok induk bentang $(\ell)=400 \mathrm{~cm}$

$h=\frac{400}{16}\left(0,4+\frac{320}{700}\right)=21,43 \mathrm{~cm}$

$\approx 30 \mathrm{~cm}$

$1,5 \leq \frac{30}{b} \leq 2 \Rightarrow \mathrm{b}=20 \mathrm{~cm}$

dimensi balok induk $20 / 30 \mathrm{~cm}$

c. Balok induk bentang $(\ell)=300 \mathrm{~cm}$

$h=\frac{300}{16}\left(0,4+\frac{320}{700}\right)=16,07 \mathrm{~cm}$

$\approx 30 \mathrm{~cm}$

$1,5 \leq \frac{30}{b} \leq 2 \Rightarrow \mathrm{b}=20 \mathrm{~cm}$

dimensi balok induk 20/30 cm 
d. Balok induk bentang $(\ell)=200 \mathrm{~cm}$

$h=\frac{200}{16}\left(0,4+\frac{320}{700}\right)=10,71 \mathrm{~cm}$

$\approx 30 \mathrm{~cm}$

$1,5 \leq \frac{30}{b} \leq 2 \Rightarrow \mathrm{b}=20 \mathrm{~cm}$

dimensi balok induk $20 / 30 \mathrm{~cm}$

e. Ring balk bentang $(\ell)=400 \mathrm{~cm}$

$h=\frac{400}{16}\left(0,4+\frac{320}{700}\right)=21,43 \mathrm{~cm}$

$\approx 25 \mathrm{~cm}$

$1,5 \leq \frac{25}{b} \leq 2 \Rightarrow \mathrm{b}=15 \mathrm{~cm}$

dimensi ring balk $15 / 25 \mathrm{~cm}$

f. Ring balk bentang $(\ell)=300 \mathrm{~cm}$

$h=\frac{300}{16}\left(0,4+\frac{320}{700}\right)=16,07 \mathrm{~cm}$

$\approx 25 \mathrm{~cm}$

$1,5 \leq \frac{25}{\mathrm{~b}} \leq 2 \Rightarrow \mathrm{b}=15 \mathrm{~cm}$

dimensi ring balk $15 / 25 \mathrm{~cm}$

2. Dimensi kolom

Dimensi kolom utama yang dipakai adalah $30 / 30 \mathrm{~cm}$.

B. Perhitungan Beban Gempa dengan Analisa Statik Ekuivalen

1. Berat total bangunan

Berat lantai $2=205785 \mathrm{~kg}$

Berat lantai $1=\frac{322660 \mathrm{~kg}+}{528445 \mathrm{~kg}}$

2. Pembatasan Waktu Getar Alami $\left(\mathrm{T}_{1}\right)$

$\mathrm{T}_{1}<0,17 \times 2$

$\mathrm{T}_{1}<0,34 \sim$ diambil $\mathrm{T}_{1}=1$ detik

3. Koefisien Gempa Dasar (C)

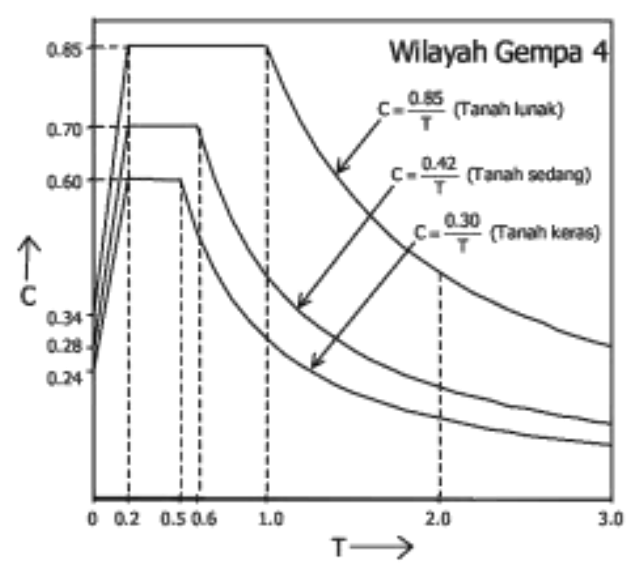

Gambar 4. Respons Spectrum Gempa Rencana WG 4 (SNI 03-1726-2002)

Dari data tanah bahwa tanah di lokasi pembangunan tergolong tanah sedang dan diasumsikan dalam wilayah gempa 4. Berdasarkan gambar (4-8) didapatkan harga: 
$\mathrm{C}=\frac{0,42}{\mathrm{~T}}=\frac{0,42}{1}=0,42$

Sehingga harga faktor respon gempa $(C)=0,42$.

1. Perhitungan Gaya Dasar Geser Nominal (V)

$$
\begin{aligned}
& \mathrm{V}=\frac{\mathrm{C}_{1} \cdot \mathrm{I}}{\mathrm{R}} \mathrm{W}_{\mathrm{t}} \\
& \mathrm{V}=\frac{0,42 \times 1}{5,6} \times(205785+322660) \\
& \mathrm{V}=39633,38 \mathrm{~kg}
\end{aligned}
$$

2. Pembagian Gaya Dasar Geser tiap Lantai

Perhitungan ini dilakukan sesuai dengan rumus (3) yang berada pada SNI 1726 Ps.

$$
\text { 6.1.3 }
$$

Portal arah $x, \frac{\mathrm{h}}{\mathrm{A}}=\frac{8}{32}=0,25<3$

Portal arah $y, \frac{\mathrm{h}}{\mathrm{A}}=\frac{8}{20}=0,40<3$, maka berlaku persamaan:

\begin{tabular}{|c|c|c|c|c|c|c|c|c|c|}
\hline \multirow{3}{*}{ LA. } & \multirow{3}{*}{$\underset{\text { (m) }}{\mathbf{h i}}$} & \multirow{3}{*}{$\begin{array}{l}\text { wi } \\
\text { (ton) }\end{array}$} & \multirow{3}{*}{$\begin{array}{c}\text { Wilii } \\
\text { (tonm) }\end{array}$} & \multirow{3}{*}{$v_{x}, y$} & \multirow{3}{*}{ Fix,y } & \multicolumn{4}{|c|}{$\begin{array}{l}\text { Untuk Tiap Portal } \\
\text { (toin) }\end{array}$} \\
\hline & & & & & & tepi & tengah & tepi & tengall \\
\hline & & & & & & $(\mathrm{H} / \mathrm{I}) \mathrm{x}$ & (L/) Fx & $(\mathrm{s}) \mathrm{Fy}$ & (1/4)Fy \\
\hline 2 & 8 & 205,79 & 1646,32 & 39,63 & 22,21 & 1,85 & 3,70 & 2,78 & 5,55 \\
\hline 1 & 4 & 322,66 & 1290,64 & 39,63 & 17,42 & 1,45 & 2,90 & 2,18 & 4,35 \\
\hline
\end{tabular}

$$
F_{i}=\frac{W_{i} \cdot Z_{i}}{\sum_{i=1}^{n} W_{i} \cdot Z_{i}} \cdot V
$$

sehingga didapat gaya geser tiap lantai seperti pada tabel berikut ini:

Tabel 3. distribusi gaya gempa pada lantai untuk tiap portal

3. Kontrol Simpangan Antar Tingkat

a. Kinerja Batas Layan $(\Delta \mathrm{s})$

Simpangan yang terjadi tidak boleh melampaui:

$\frac{0,03}{\mathrm{R}} \times \mathrm{h}_{\mathrm{i}}=\frac{0,03}{5,6} \times 4000=21,43 \mathrm{~mm}$ atau $30 \mathrm{~mm}$

Tabel 4. Analisa $\Delta$ s akibat gaya gempa

\begin{tabular}{cccccc}
\hline Lt. & $\begin{array}{c}\text { hx } \\
(\mathrm{m})\end{array}$ & $\begin{array}{c}\Delta s \\
(\mathrm{~mm})\end{array}$ & $\begin{array}{c}\text { drift } \Delta \mathrm{s} \\
\text { antar } \\
\text { tingkat } \\
(\mathrm{mm})\end{array}$ & $\begin{array}{c}\Delta \mathrm{syarat} \\
(\mathrm{mm})\end{array}$ & keterangan \\
\hline 2 & 8 & 7,60 & 4,50 & 21,43 & OK \\
\hline 1 & 4 & 3,10 & 3,10 & 21,43 & OK \\
\hline
\end{tabular}


b. Kinerja Batas Ultimate $(\Delta \mathrm{m})$

Kinerja Batas Ultimate $(\Delta \mathrm{m})$ tidak boleh lebih dari 0,02 kali tinggi tingkat $(\Delta \mathrm{M} \leq 0,02 \mathrm{~h})$.

Tabel 5. Analisa $\Delta \mathrm{m}$ akibat gaya gempa

\begin{tabular}{cccccc}
\hline Lt. & $\begin{array}{c}\text { hx } \\
(\mathrm{m})\end{array}$ & $\begin{array}{c}\text { drift } \Delta \mathrm{s} \\
\text { antar } \\
\text { tingkat } \\
(\mathrm{mm})\end{array}$ & $\begin{array}{c}\text { drit } \Delta \mathrm{mm} \\
\text { antar } \\
\text { tingkat } \\
(\mathrm{mm})\end{array}$ & $\begin{array}{c}\text { syarat drift } \\
(\mathrm{mm})\end{array}$ & keterangan \\
\hline 2 & 8 & 4,50 & 4.28 & 80 & OK \\
\hline 1 & 4 & 3,10 & 2,95 & 80 & OK \\
\hline
\end{tabular}

c. Kontrol Pengaruh P- $\Delta$ pada kolom

Sesuai dengan ketentuan UBC didapatkan bahwa drift $\Delta$ s antar tingkat $<0,02$ hi / $\mathrm{R}$ yaitu:

$<(0,02 \times 4000) / 5,6$

$<14,286 \mathrm{~mm}$ (tidak perlu perhitungan P- $\Delta$ efek)

\section{Hasil Analisa Balok}

1. Penulangan lentur tumpuan balok
a. Tulangan lapangan atas dipasang $4 \varnothing 16\left(\mathrm{As}=803,84 \mathrm{~mm}^{2}\right)$.
b. Tulangan lapangan bawah dipasang $2 \varnothing 16\left(\mathrm{As}=401,92 \mathrm{~mm}^{2}\right)$.
c. Tulangan geser dipasang $\quad \varnothing 10-100 \mathrm{~mm}$.

2. Penulangan lentur tumpuan balok

a. Tulangan lapangan atas dipasang $2 \varnothing 16\left(\mathrm{As}=401,92 \mathrm{~mm}^{2}\right)$.

b. Tulangan lapangan bawah dipasang $2 \varnothing 16\left(\mathrm{As}=401,92 \mathrm{~mm}^{2}\right)$.

c. Tulangan geser dipasang $\quad \varnothing 10-200 \mathrm{~mm}$.
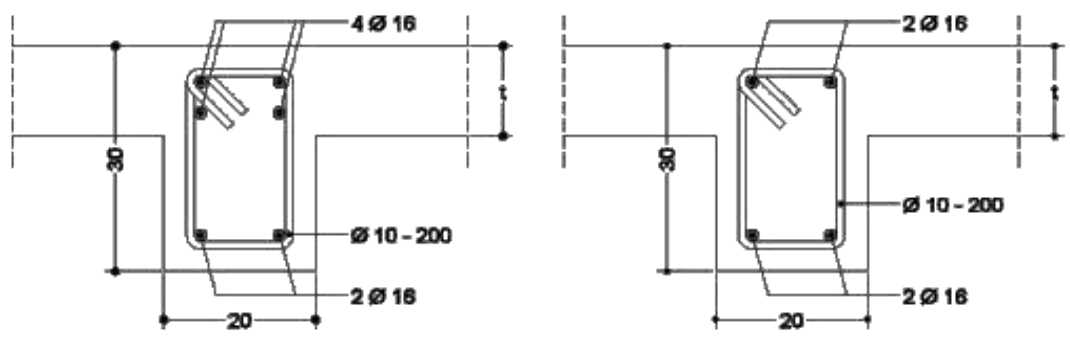

Gambar 5. Penampang melintang balok 


\section{Hasil Analisa Kolom}

1. Tulangan utama kolom lantai satu dan lantai dua $=8 \varnothing 16$ atau dengan persentase $1,79 \%$ dari luas penampang bruto kolom. Persentase tulangan kedua kolom ini sesuai syarat SNI 03-2847-2002 Ps. 23.4.3.1 yaitu harus antara 1\% - 6\% telah dipenuhi.

2. Tulangan sengkang pada daerah tumpuan digunakan $=\varnothing 10-100 \mathrm{~mm}$. sedangkan tulangan sengkang pada daerah lapangan digunakan $=\varnothing 10-150 \mathrm{~mm}$
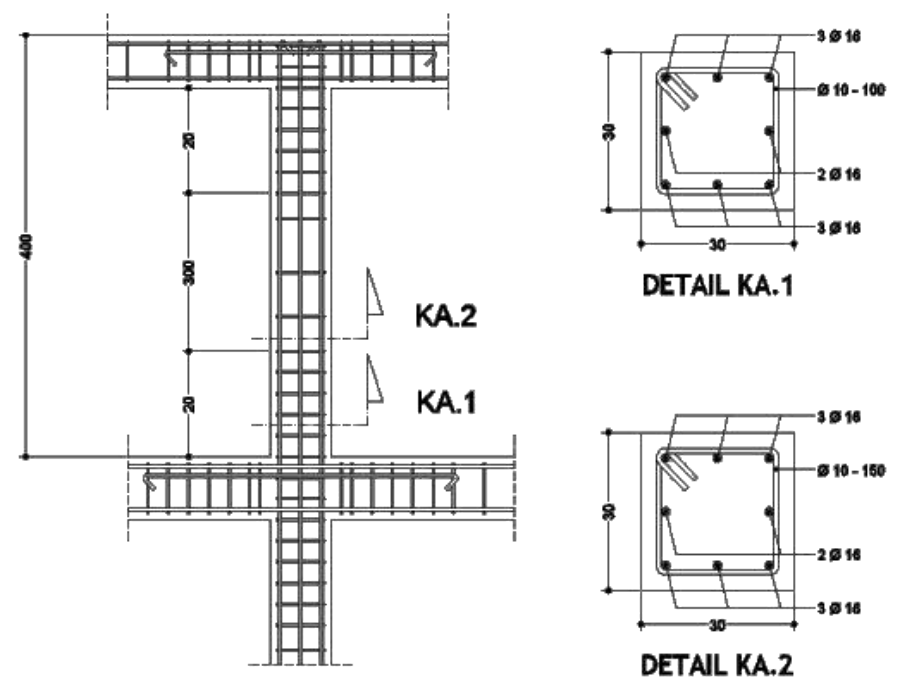

Gambar 6. Penampang memanjang dan melintang kolom

\section{E. Hasil Analisa Hubungan Balok Kolom}

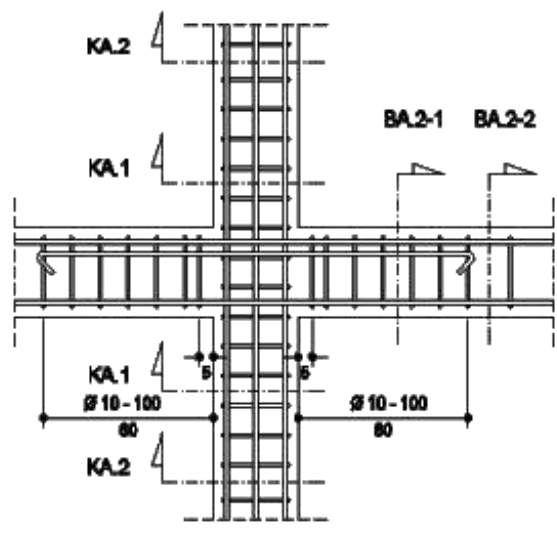

HBK Tengah

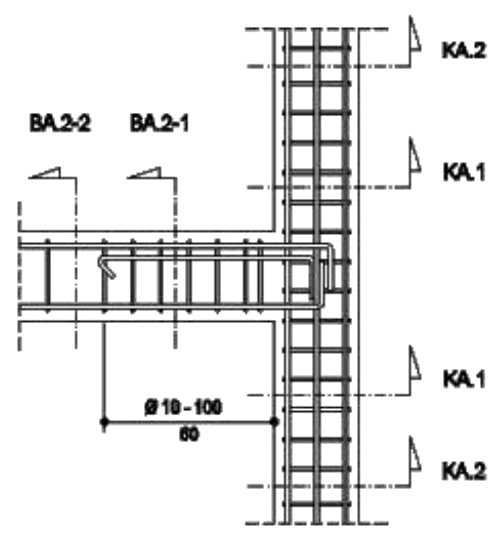

HBK Tepi

Gambar 7. Penampang memanjang hubungan balok kolom 


\section{Kesimpulan}

Dari tinjauan desain struktur portal yang telah dilakukan, diambil kesimpulan bahwa dengan asumsi pembebanan yang sama pada konstruksi gedung yang sama, tetapi menggunakan metode perencanaan dengan sistem struktur yang berbeda, yang awalnya menggunakan Sistem Rangka Pemikul Momen Khusus (SRPMK), kemudian ditinjau dengan menggunakan Sistem Rangka Pemikul Momen Menengah (SRPMM), diperoleh desain yang memenuhi persyaratan keamanan untuk menahan gaya-gaya yang bekerja pada struktur portal gedung Administrasi Pusat STAIN Sorong. Sehingga perancangan struktur gedung ini seharusnya tidak perlu menggunakan SRPMK.

\section{Ucapan Terima Kasih}

Terima kasih kepada pihak Program Studi Teknik Sipil Fakultas Teknik Universitas Muhammadiyah Sorong dengan berbagai fasilitas pendukungnya sehingga penelitian ini dapat selesai sesuai dengan rencana.

\section{Daftar Pustaka}

Anonym, (1983). Peraturan Pembebanan Indonesia Untuk Gedung. 1983. Bandung: Departemen Pekerjaan Umum.

Anonym, (2002). RSNI 03-1727-1989: Tata Cara Perhitungan Pembebanan Untuk Bangunan Rumah dan Gedung 2002. Badan Standardisasi Nasional.

Anonym, (2002). SNI 03-1726-2002: Tata Cara Perencanaan Ketahanan Gempa Untuk Bangunan Gedung. 2002. Badan Standardisasi Nasional.

Gunawan, T. \& Margaret, S. (1988). Diktat Teori Soal Dan Penyelesaian Konstruksi Beton I . Jilid 2. 2003 Jakarta: Delta Teknik Group.

Kusuma, G. H. \& Vis, W. C. (1993). Dasar-Dasar Perencanaan Beton Bertulang. Erlangga. Jakarta.

Pristianto, H., Amri, I., \& Rusdi, A. (2014, May 9). Pedoman Penulisan Tugas Akhir Fakultas Teknik Universitas Muhammadiyah $\quad$ Sorong 2014. http://doi.org/10.17605/OSF.IO/4VTJM.

Purwono, R., Tavio, Imran, I. \& Raka, G. P. (2007). Tata Cara Perhitungan Struktur Beton Untuk Bangunan Gedung (SNI 03-2847-2002) Dilengkapi Penjelasan (S-2002). ITS Press. Surabaya.

Saragih, E( 2010). Kompilasi Bahan Ajar Aplikasi SAP 2000. Sorong

Sunggono, Kh. (1995). Buku Teknik Sipil. NOVA. Bandung.

Wigroho, Y. H. (2001). Analisis \& Perancangan Struktur Frame Menggunakan SAP 2000 Versi 7.42. Andi. Yogyakarta. 